\title{
Advanced Donor Age Impairs Bone Marrow Cell Therapeutic Efficacy for Cardiac Disease
}

\author{
Xiaoyin Wang ${ }^{1 \#}$ Junya Takagawa ${ }^{2,3 \#}$ Daniel J. Haddad ${ }^{1}$ Kranthi Pinnamaneni ${ }^{1}$ Yan Zhang ${ }^{2,4}$ Richard E. Sievers $^{2}$ William Grossman $^{1,2}$ Yerem $^{2}$ \\ Yeghiazarians ${ }^{2,5}$ and Matthew L. Springer ${ }^{1,2,5 *}$ \\ ${ }^{1}$ Cardiovascular Research Institute, University of California, San Francisco, San Francisco, CA 94143, USA \\ ${ }^{2}$ Division of Cardiology, University of California, San Francisco, San Francisco, CA 94143, USA \\ ${ }^{3}$ Current address: Department of Cardiology, Imizu City Hospital, Imizu City, Toyama 934-0053, Japan \\ ${ }^{4}$ Current address: Silver Creek Pharmaceuticals, San Francisco, CA 94158, USA \\ ${ }^{5}$ Eli and Edythe Broad Center of Regeneration Medicine and Stem Cell Research, University of California, San Francisco, San Francisco, CA 94143, USA \\ \#These authors provided equal contribution
}

\begin{abstract}
Therapeutic results of clinical autologous bone marrow cell (BMC) therapy trials for cardiac disease have been modest compared to results of BMC implantation into rodent hearts post-myocardial infarction (MI). In clinica trials, autologous BMCs are typically harvested from older patients who have recently suffered an MI. In contrast, experimental studies in rodent models typically utilize donor BMCs isolated from young, healthy, inbred mice that are not the recipients. Using unfractionated BMCs from donor mice at ages of young, middle-aged, and old, we discovered that recipient left ventricular function post-MI was significantly improved by young donor BMC implantation but was only preserved by middle-aged donor BMCs. Notably, old donor BMCs did not slow the decline in recipient post-MI cardiac function, suggesting BMC impairment by advanced donor age. Furthermore, we also show here that BMCs that are therapeutically impaired by donor age can be further impaired by concurrent donor MI. In conclusion, our findings suggest that therapeutic impairment of BMCs by advanced age is one of the important factors that can limit the success of clinical autologous BMC-based therapy.
\end{abstract}

Keywords: Advanced age; Bone marrow cells; Ejection fraction; Myocardial infarction

Abbreviations: BMCs: Bone marrow cells; EDV: End-diastolic volume; EF: Ejection fraction; ESV: End-systolic volume; HBSS: Hank's balanced salt solution; MI: Myocardial infarction

\section{Introduction}

Implantation of bone marrow cells (BMCs) into the infracted heart has been shown to be therapeutic through improvement of left ventricular function after myocardial infarction (MI) and limitation of infarct size in rodent MI models [1-3], but human clinical trials of BMC-based therapy for cardiac disease have achieved more modest results [4-6]. Rodent experiments involve BMCs from distinct inbred donor mice that are typically young, and thus may poorly represent clinical autologous cell therapy, in which delivered cells are from patients who have had an MI and who are typically older. We have reported that donor MI triggers an inflammatory response that impairs the therapeutic potential of BMCs in a mouse model of MI, making the donor BMCs less able to prevent a decline in left ventricular function when implanted into post-MI recipient hearts [7]. Moreover, aging impairs not only the functional activity of various populations of cells isolated from bone marrow or blood of aged animals [8,9] and elderly human patients $[10,11]$ but also the beneficial effect of cytoprotective compounds or growth factors on post-MI remodeling [12]. Recently, Ayala-Lugo et al. [13] reported that BMCs from moderately aged donor rats ( 1 year) are less therapeutic for MI than those from young rats. However, the effect of advanced age ( $>2$ years old in mice) on the therapeutic efficacy of unfractionated BMCs for treating MI is relatively unexplored. We show here that advanced age drastically impairs the therapeutic efficacy of the donor BMCs, irrespective of the state of the recipient heart, and that the anti-therapeutic effects of donor age and donor MI on BMCs are additive.

\section{Materials and Methods}

All animal experiments were approved by the Institutional Animal Care and Use Committee of the University of California, San Francisco.

\section{Donor and recipient mice}

Male C57BL/6J mice were obtained from the Jackson Laboratory (Bar Harbor, ME). Young donor mice were at age 10 weeks. Middleaged donor mice were housed for 1 year before use. Old donor mice were housed for 2.5 years before use (the typical mouse life-span is 2-3 years). Recipient mice were at 10 weeks of age. Recipient group size was 12 or greater; BMCs from 1 donor mouse were used per 5 recipient mice.

\section{Myocardial infarction}

MI was surgically induced as described previously [14]. Mice were anesthetized with $2 \%$ isoflurane and received analgesics (buprenorphine $0.1 \mathrm{mg} / \mathrm{kg}$, subcutaneous injection) at time of surgery. Hearts were exposed via a parasternotomy and the left anterior descending coronary artery was permanently ligated $\sim 3 \mathrm{~mm}$ below the tip of the left atrium.

\section{BMC harvest and injection}

The protocol for BMC harvest and injection has been previously

*Corresponding author: Matthew L. Springer, Division of Cardiology, University of California, San Francisco, San Francisco, California 94143, USA, Tel: 415-5028404; Fax: 415-353-9190; E-mail: matt.springer@ucsf.edu

Received November 02, 2011; Accepted November 16, 2011; Published November 18, 2011

Citation: Wang X, Takagawa J, Haddad DJ,Pinnamaneni K, Zhang Y, et al. (2011) Advanced Donor Age Impairs Bone Marrow Cell Therapeutic Efficacy for Cardiac Disease. J Tissue Sci Eng S3:002. doi:10.4172/2157-7552.S3-002

Copyright: ( 2011 Wang X, et al. This is an open-access article distributed unde the terms of the Creative Commons Attribution License, which permits unrestricted use, distribution, and reproduction in any medium, provided the original author and source are credited. 
described [3,14]. Briefly, mouse femurs and tibias were harvested, and bone marrow was flushed with cold Hank's balanced salt solution (HBSS) with $0.5 \%$ BSA. The suspension was strained through a 70 $\mu \mathrm{m}$ filter and washed twice with HBSS. After centrifugation, the unfractionated whole BMCs were harvested for injection. The cell concentration was adjusted to $10^{8}$ viable cells $/ \mathrm{ml} .10^{6}$ cells were injected into myocardium at the infarct border zone as two $5 \mu \mathrm{l}$ injections under ultrasound visualization using a Vevo660 micro-ultrasound system (VisualSonics Inc., Toronto) [14].

Each donor mouse provided BMCs for 5 recipient mice in order to have multiple donors per group. BMCs were always implanted into recipient hearts on day 3 post-MI. Injection of HBSS served as a negative control. The allocation of BMC treatment for MI recipients was random and $98 \%$ of intramyocardial injections were judged to be optimal based on visible changes in localized ultrasound signal resulting from the presence of cell suspension [3,7,15]. Recipient mouse conditions were always constant and all were injected on day 3 post-MI (a stage of physiological response to MI comparable to that used in the clinic) through ultrasound-guidance [14].

\section{Echocardiography}

Echocardiography of recipients was performed under anesthesia with $1.25 \%$ isoflurane at baseline, and 2 and 28 days post-MI using a Vevo660 micro-ultrasound system as described previously $[7,15]$. Echocardiograms were obtained at long-axis view to measure the left ventricular end-systolic volume (ESV) and end-diastolic volume (EDV). Formula of the left ventricular ejection fraction (EF): EF (\%) $=[(\mathrm{EDV}-\mathrm{ESV}) / \mathrm{EDV}] \times 100$. Wall thickness was measured at the apical-segment (infarct) and mid-segment (infarct border zone) of the anterior wall and at the basal segment of the anterior and posterior walls, respectively. Echocardiographic parameters were measured/remeasured by two blinded researchers.

\section{Histological measurement of infarct size}

Mouse hearts were arrested in diastole with saturated $\mathrm{KCl}$ injected into the left ventricular chamber and removed. Frozen heart sections were analyzed histologically for infarct size measurement as described previously [16].

\section{Statistical analysis}

All values are presented as mean \pm SD. Differences were determined by two-way repeated measures ANOVA with subsequent Bonferroni's post hoc test to compare means between multiple $(>2)$ groups on days 2 and 28 post-MI, by one-way ANOVA with Bonferroni's post hoc test to compare means between multiple groups and by two-tailed paired $t$ test to compare means between day 2 and day 28 post-MI in each group. A value of $P<0.05$ was considered to be statistically significant.

\section{Results}

\section{Impairment of BMC therapeutic potential by advanced donor age}

To confirm if donor advanced age impairs the therapeutic potential of BMCs for treatment of MI, we implanted donor BMCs into groups of infarcted recipient mice, keeping the recipient conditions constant but varying the donor conditions with respect to age. Recipient echocardiographic parameters were measured by two blinded researchers and found to be consistent.

Following MI, in all groups, recipient left ventricular EF declined uniformly from a baseline of $50.1 \pm 3.8 \%$ to $32.0 \pm 3.8 \%$ on day 2 postMI before cell implantation, as shown in Table 1 and Figure $1 \mathrm{~A}$. Injection of HBSS vehicle on day 3 permitted continued deterioration of EF to day $28(21.4 \pm 6.4 \%$ versus $31.8 \pm 3.5 \%$ for day $2, P<0.0001)$. In contrast, young donor BMCs improved recipient 28 day post-MI EF (39.0 $\pm 5.9 \%$ versus $32.1 \pm 3.4 \%$ for day $2, P<0.001)$, while middle-aged donor BMCs only preserved recipient 28 day post-MI EF $(32.6 \pm 3.8 \%$ versus $31.7 \pm 4.1 \%$ for day $2, P=\mathrm{N}$.S.). Notably, old donor BMCs did not stem the decline in recipient 28 day post-MI EF (23.8 $\pm 5.5 \%$ versus $32.3 \pm 4.3 \%$ for day $2, P<0.0001$ ), comparable to the negative control HBSS, despite consistently good viability ( $96 \%$ assessed by trypan blue staining) in all BMCs assessed before implantation. Figure $1 \mathrm{~B}$ shows that by day 28 post-MI, young donor BMCs, but not middle-aged

\begin{tabular}{|c|c|c|c|c|c|c|c|}
\hline $\begin{array}{l}\text { Donor condition } \\
\text { (recipient number) }\end{array}$ & $\begin{array}{l}\mathrm{EF} \\
\%\end{array}$ & $\begin{array}{c}\text { ESV } \\
\mu \mathrm{l}\end{array}$ & $\begin{array}{c}\text { EDV } \\
\mu l\end{array}$ & $\begin{array}{l}\text { AWTd } \\
\mathrm{mm}\end{array}$ & $\begin{array}{l}\text { PWTd } \\
\mathrm{mm}\end{array}$ & $\begin{array}{l}\text { Border zone } \\
\mathrm{mm}\end{array}$ & $\begin{array}{c}\text { Infarct } \\
\mathrm{mm}\end{array}$ \\
\hline $\begin{array}{l}\text { Young }(n=15) \\
\text { Baseline } \\
\text { Day } 2 \text { post-MI } \\
\text { Day } 28 \text { post-MI }\end{array}$ & $\begin{array}{l}50.1 \pm 2.2 \\
32.1 \pm 3.4^{*} \\
39.0 \pm 5.9^{\star \ddagger}\end{array}$ & $\begin{array}{l}33.2 \pm 3.4 \\
42.1 \pm 5.6^{*} \\
41.2 \pm 6.7^{\dagger}\end{array}$ & $\begin{array}{l}66.4 \pm 5.1 \\
61.9 \pm 7.3 \\
67.6 \pm 9.6\end{array}$ & $\begin{array}{l}0.73 \pm 0.04 \\
0.72 \pm 0.04\end{array}$ & $\begin{array}{l}0.69 \pm 0.05 \\
0.67 \pm 0.05\end{array}$ & $\begin{array}{l}0.63 \pm 0.04 \\
0.59 \pm 0.04^{\ddagger}\end{array}$ & $\begin{array}{l}0.51 \pm 0.06 \\
0.49 \pm 0.06\end{array}$ \\
\hline $\begin{array}{l}\text { Middle-aged }(n=12) \\
\text { Baseline } \\
\text { Day } 2 \text { post-MI } \\
\text { Day } 28 \text { post-MI }\end{array}$ & $\begin{array}{l}50.6 \pm 4.0 \\
31.7 \pm 4.1^{*} \\
32.6 \pm 3.8^{\text {* }}\end{array}$ & $\begin{array}{l}34.4 \pm 3.4 \\
42.6 \pm 8.9^{*} \\
56.4 \pm 12.3^{*} \neq\end{array}$ & $\begin{array}{l}69.5 \pm 4.0 \\
62.5 \pm 12.8 \\
83.5 \pm 16.3^{\# \bullet \bullet}\end{array}$ & $\begin{array}{l}0.73 \pm 0.04 \\
0.70 \pm 0.03\end{array}$ & $\begin{array}{l}0.73 \pm 0.04 \\
0.70 \pm 0.03\end{array}$ & $\begin{array}{l}0.62 \pm 0.04 \\
0.55 \pm 0.08^{\ddagger}\end{array}$ & $\begin{array}{l}0.52 \pm 0.08 \\
0.46 \pm 0.09\end{array}$ \\
\hline $\begin{array}{l}\text { Old }(n=17) \\
\text { Baseline } \\
\text { Day } 2 \text { post-MI } \\
\text { Day } 28 \text { post-MI }\end{array}$ & $\begin{array}{l}50.1 \pm 4.6 \\
32.3 \pm 4.3^{\star} \\
23.8 \pm 5.5^{\star \S \Omega}\end{array}$ & $\begin{array}{l}33.1 \pm 5.9 \\
43.0 \pm 9.0^{\dagger} \\
78.3 \pm 28.1^{\star \ddagger \Omega}\end{array}$ & $\begin{array}{l}65.9 \pm 8.6 \\
63.5 \pm 11.5 \\
101.7 \pm 31.2^{+\S \|_{\infty}}\end{array}$ & $\begin{array}{l}0.71 \pm 0.03 \\
0.63 \pm 0.05^{\S \Omega}\end{array}$ & $\begin{array}{l}0.71 \pm 0.02 \\
0.66 \pm 0.04 \ddagger \Delta\end{array}$ & $\begin{array}{l}0.61 \pm 0.07 \\
0.47 \pm 0.07 \S \| \infty\end{array}$ & $\begin{array}{l}0.51 \pm 0.05 \\
0.38 \pm 0.06^{\S^{\mathrm{n} \infty}}\end{array}$ \\
\hline $\begin{array}{l}\text { HBSS }(n=14) \\
\text { Baseline } \\
\text { Day } 2 \text { post-MI } \\
\text { Day } 28 \text { post-MI }\end{array}$ & $\begin{array}{l}50.1 \pm 4.4 \\
31.8 \pm 3.5^{\star} \\
21.4 \pm 6.4^{\star \S \Omega}\end{array}$ & $\begin{array}{l}33.3 \pm 4.7 \\
42.9 \pm 6.3^{*} \\
82.5 \pm 26.0^{* \pm \Omega}\end{array}$ & $\begin{array}{l}66.7 \pm 6.3 \\
62.9 \pm 7.9 \\
103.4 \pm 25.5^{\star \S \|_{\infty}}\end{array}$ & $\begin{array}{l}0.73 \pm 0.02 \\
0.67 \pm 0.04 \S \Omega\end{array}$ & $\begin{array}{l}0.71 \pm 0.02 \\
0.70 \pm 0.01\end{array}$ & $\begin{array}{l}0.63 \pm 0.03 \\
0.46 \pm 0.09 \S \|_{\infty}\end{array}$ & $\begin{array}{l}0.54 \pm 0.06 \\
0.33 \pm 0.09 \S \Omega\end{array}$ \\
\hline
\end{tabular}

AWTd, anterior wall thickness in diastole; BMCs, bone marrow cells; EDV, end-diastolic volume; EF, ejection fraction; ESV, end-systolic volume; HBSS, Hank's balanced salt solution; MI, myocardial infarction; PWTd, posterior wall thickness in diastole. * $P<0.0001$ vs baseline; $† P<0.01$ vs baseline; \# $P<0.05$ vs baseline; $\S P<0.0001$ vs day 2 post-Ml; $\ddagger P<0.01$ vs day 2 post-Ml; $\diamond P<0.05$ vs day 2 post-Ml; $\| P<0.001$ vs young donor group; $\propto P<0.01$ vs young donor group; $\triangle P<0.05$ vs young donor group; $\Omega$ $P<0.001$ vs young and middle-aged donor groups; $\infty P<0.05$ vs middle-aged donor group; and $\Delta P<0.01$ vs middle-aged donor group and HBSS control group.

Table 1: Recipient echocardiographic parameters before (day 2 post-MI) and after (day 28 post-MI) the implantation of BMCs from donors at different ages. 

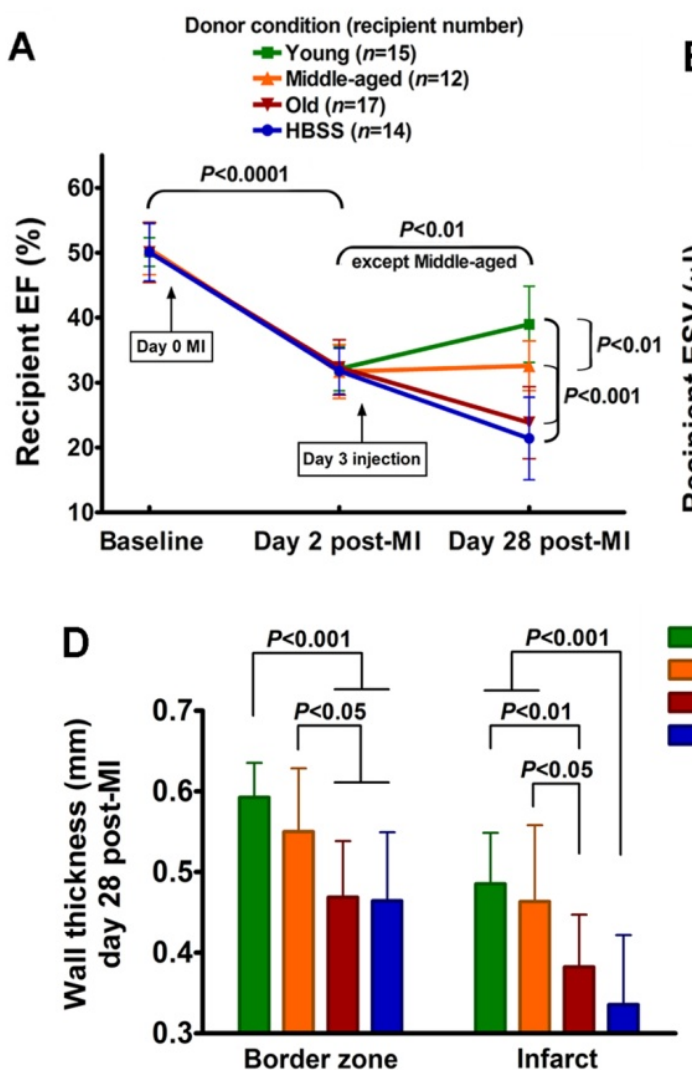
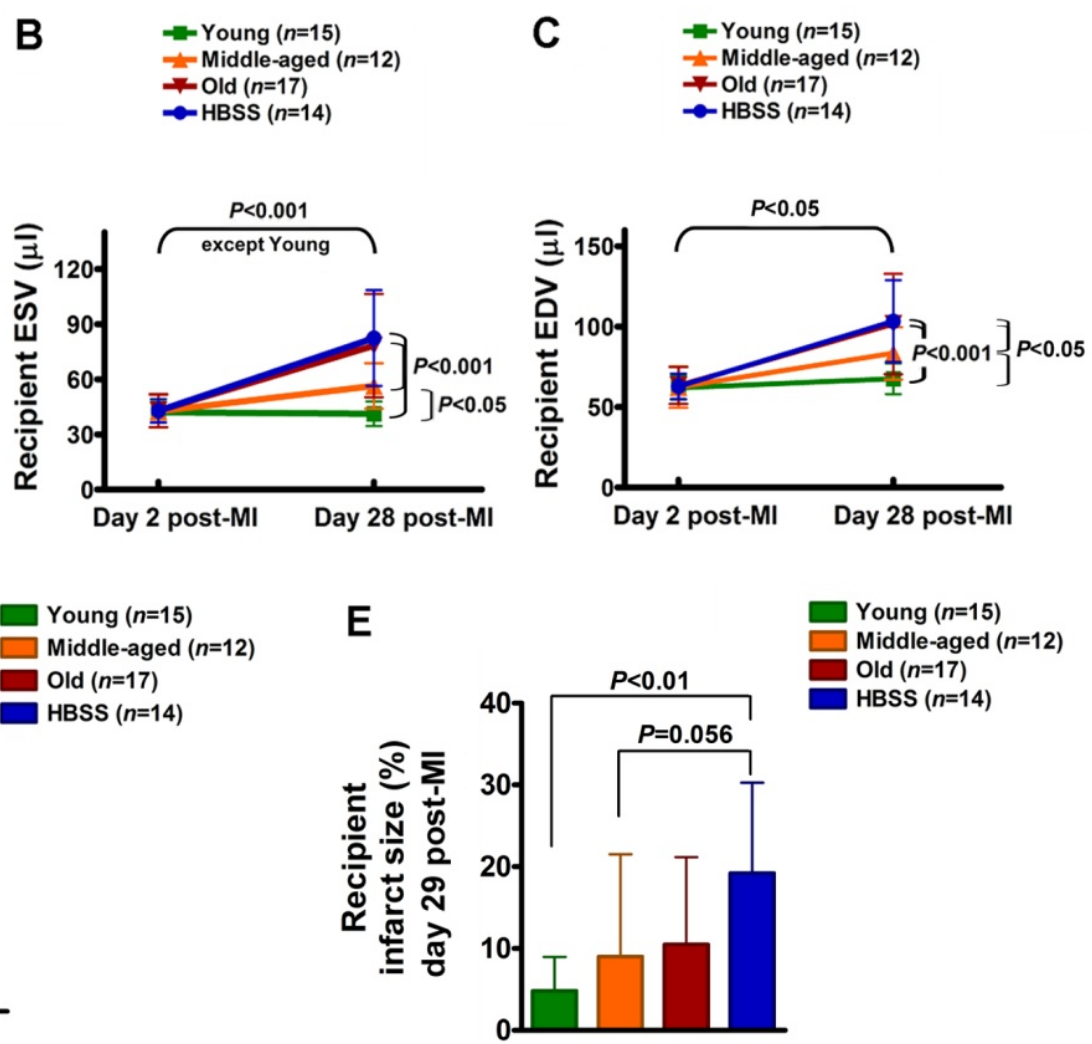

Figure 1: Influence of donor age on BMC therapeutic potential for treatment of recipient MI. Implanted BMCs were harvested from donor mice at ages of young, middleaged and old. HBSS served as a negative control. (A) Recipient left ventricular ejection fraction (EF) at baseline, day 2 post-MI and day 28 post-MI. (B) Recipient left ventricular end-systolic volume (ESV). (C) Recipient end-diastolic volume (EDV). (D) Recipient anterior wall thickness at border zone and infarct area. (E) Recipient infarct size at day 29 post-Ml, expressed as a rough percentage of the left ventricle that is occupied by infarct scar

donor BMCs, prevented an increase in recipient ESV, which both were significantly different from the deterioration seen in groups receiving BMCs from old donors or HBSS (day 28 ESV: $41.2 \pm 6.7 \mu$ for young donors and $56.4 \pm 12.3 \mu \mathrm{l}$ for middle-aged donors versus $78.3 \pm 28.1 \mu \mathrm{l}$ for old donors and $82.5 \pm 26.0 \mu \mathrm{l}$ for HBSS, $P<0.001$ ). Although none of the donor BMC conditions prevented an increase in recipient EDV (Figure 1C), the 28 day post-MI EDV of the group receiving BMCs from young donors was significantly smaller than in that receiving BMCs from middle-aged donors, which both were significantly different from those receiving BMCs from old donors or HBSS (day 28 EDV: 67.6 \pm 9.6 $\mu \mathrm{l}$ for young donors and $83.5 \pm 16.3 \mu \mathrm{l}$ for middle-aged donors versus $101.7 \pm 31.2 \mu \mathrm{l}$ for old donors and $103.4 \pm 25.5 \mu \mathrm{l}$ for HBSS, $P<0.05$ ). In the young and middle-aged donor groups, recipient anterior wall thickness at the infarct and border zone was significantly thicker than those in the old donor group and HBSS group (Figure 1D). Recipient infarct size in the young donor group was significantly smaller than that in the HBSS group (Figure 1E).

\section{Additive impairment of aged BMC potential by donor MI}

Because we have recently reported that donor MI impairs BMC therapeutic potential by an MI-triggered inflammatory response [7], we further determined whether BMCs already impaired by donor age could be further impaired by donor MI. After implantation of BMCs from aged/MI donors, middle-aged-infarcted donor BMCs no longer preserved recipient 28 day post-MI EF, representing an additive impairment by both donor middle-age and donor MI (Figure 2A). However, recipient day 28 post-MI EF after implantation with oldinfarcted donor BMCs was almost identical to that resulting from implantation with old-healthy donor BMCs, because implantation of old-donor BMCs already was comparable to injection of negative control HBSS (Figure 2B).

\section{Discussion}

Clinical trials of BMC therapy for MI have had limited success relative to the rodent experiments on which they were based. One substantial difference between the two situations stems from the fact that clinical patients undergoing autologous BMC therapy have had a recent $\mathrm{MI}$ and tend to be middle-aged or older. In contrast, harvest of bone marrow from mice requires euthanasia of the donor mouse, so rodent BMC therapy experiments cannot be autologous and involve different donor animals that are typically healthy and young. Thus, the cells being used in rodent experiments are a poor approximation of actual BMCs used for clinical autologous cell therapy. We used a mouse model in which the BMC donors and recipients were separate individuals, which is not practical in autologous human cell transplants. This enabled us to study the effects of the donor condition specifically by varying the age of the donor mice to make the rodent model look more like the clinical situation for this isolated parameter, the impact of age on the BMCs being harvested and administered. BMCs from old donor mice were remarkably devoid of therapeutic benefit, leaving 
A $\Rightarrow$ Middle-aged-healthy $(n=12) \quad \sim$ Middle-aged-infarcted $(n=10)$

HBSS $(n=14)$
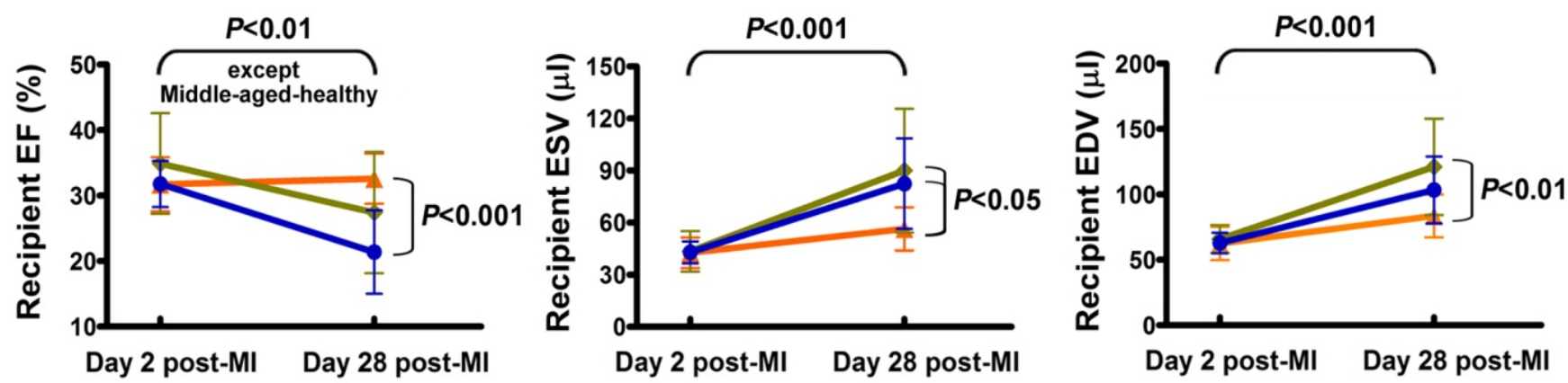

B

$\mp$ Old-healthy $(n=17) \quad 7$ Old-infarcted $(n=14)$

HBSS $(n=14)$
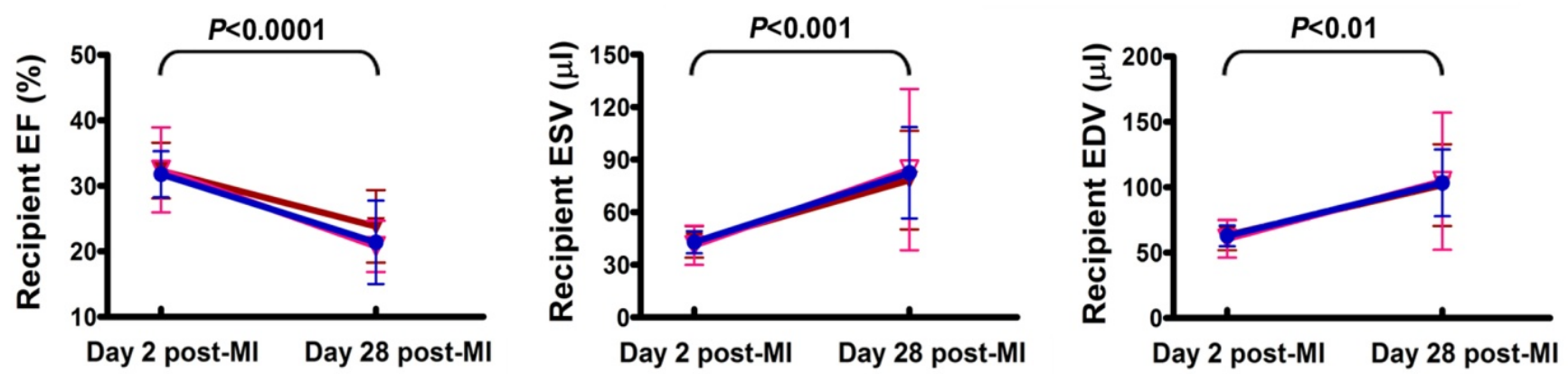

Figure 2: Additive impairment of aged BMC therapeutic potential by donor MI. (A) Reduced therapeutic effect of middle-aged donor BMCs was further reduced by donor MI. (B) Old-healthy and old-infarcted donor BMCs were identically ineffective.

them incapable of preventing the decline in recipient left ventricular function post-MI when implanted into recipient hearts.

The emphasis of this study was on the effects of donor age mostly because while aging studies involving cell therapy tend to focus on the age of the recipient heart itself [12,17], our study isolates the age state of the BMC donor from that of the recipient, in the setting of recipient acute MI. This approach has been used to demonstrate cardiac therapeutic impairment of unfractionated BMCs by acute MI [7], of bone marrow stromal cells by advanced age [9], and of bone marrow mononuclear cells by middle-age [13]. A body of literature suggests that age can cause shortening of telomeres or reductions in various molecular or functional properties of cells in the bone marrow [18-23]. Circulating angiogenic cells (sometimes called endothelial progenitor cells) from bone marrow and peripheral blood exhibit agerelated reductions in various functional parameters in vitro, such as reduced migration toward chemoattractants and ability to decrease atherosclerosis $[8,10,24]$. Therefore, BMCs in general from old animals may suffer from a lifetime of progressive impairment, causing gradual functional declines.

Importantly, this therapeutic impairment is intrinsic to the cells, which exhibit an age-dependent decrease in cellular therapeutic potential, and is independent of the response of the recipient. Recently published evidence [13] suggests that alterations in the cellular distribution and certain cell properties in the bone marrow from middle-aged donors may contribute to the therapeutic impairment of donor BMCs, although this interpretation is complicated by our previous finding that implanted BMCs do not need to be alive to improve cardiac function post-MI [3], and future experiments will be needed to determine the impact of cellular functional changes on the therapeutic efficacy of aged BMCs. As we have demonstrated, BMC therapeutic potential can be additively impaired by both age and MI, suggesting that clinical autologous cell therapy trials face at least two practical challenges not reflected in typical rodent experiments. Because use of allogeneic cells from young, healthy individuals would result in life-long immunosupression, it will be important to determine how to prevent this decline in therapeutic impairment in aged individuals. Current research is geared toward elucidating the crucial differences between young and aged BMCs that might be reversed or prevented before delivery in a clinical setting. In summary, our findings provide one potential explanation of why human trials have not matched the level of success of the rodent experiments, and suggest that advanced age is one of the important factors that limit the success of clinical autologous BMC-based therapy.

\section{Acknowledgments}

This research was supported by NIH grants R01 HL 086917, R03 EB005802, and R21 HL097129, UC Discovery Grant bio04-10481, and a grant from the Wayne and Gladys Valley Foundation. All other authors have reported that they have no relationships and no competing interests to disclose.

\section{References}

1. Orlic D, Kajstura J, Chimenti S, Jakoniuk I, Anderson SM, et al. (2001) Bone marrow cells regenerate infarcted myocardium. Nature 410: 701-705.

2. Gnecchi M, He H, Liang OD, Melo LG, Morello F, et al. (2005) Paracrine action accounts for marked protection of ischemic heart by Akt-modified mesenchymal stem cells. Nat Med 11: 367-368.

3. Yeghiazarians $Y$, Zhang $Y$, Prasad M, Shih H, Saini SA, et al. (2009) Injection of 
Citation: Wang X, Takagawa J, Haddad DJ,Pinnamaneni K, Zhang Y, et al. (2011) Advanced Donor Age Impairs Bone Marrow Cell Therapeutic Efficacy for Cardiac Disease. J Tissue Sci Eng S3:002. doi:10.4172/2157-7552.S3-002

bone marrow cell extract into infarcted hearts results in functional improvement comparable to intact cell therapy. Mol Ther 17: 1250-1256.

4. Rosenzweig A (2006) Cardiac cell therapy--mixed results from mixed cells. N Engl J Med 355: 1274-1277.

5. Wollert KC, Meyer GP, Lotz J, Ringes-Lichtenberg S, Lippolt P, et al. (2004) Intracoronary autologous bone-marrow cell transfer after myocardial infarction: the BOOST randomised controlled clinical trial. Lancet 364: 141-148.

6. Schachinger V, Erbs S, Elsasser A, Haberbosch W, Hambrecht R, et al (2006) Intracoronary bone marrow-derived progenitor cells in acute myocardial infarction. N Engl J Med 355: 1210-1221.

7. Wang X, Takagawa J, Lam VC, Haddad DJ, Tobler DL, et al. (2011) Donor myocardial infarction impairs the therapeutic potential of bone marrow cells by an interleukin-1-mediated inflammatory response. Sci Transl Med 3: 100ra90.

8. Rauscher FM, Goldschmidt-Clermont PJ, Davis BH, Wang T, Gregg D, et al (2003) Aging, progenitor cell exhaustion, and atherosclerosis. Circulation 108 457-463.

9. Zhang H, Fazel S, Tian H, Mickle DA, Weisel RD, et al. (2005) Increasing donor age adversely impacts beneficial effects of bone marrow but not smooth muscle myocardial cell therapy. Am J Physiol Heart Circ Physiol 289: H2089-2096.

10. Heiss C, Keymel S, Niesler U, Ziemann J, Kelm M, et al. (2005) Impaired progenitor cell activity in age-related endothelial dysfunction. J Am Coll Cardiol 45: $1441-1448$

11. Scheubel RJ, Zorn H, Silber RE, Kuss O, Morawietz H, et al. (2003) Agedependent depression in circulating endothelial progenitor cells in patients undergoing coronary artery bypass grafting. J Am Coll Cardiol 42: 2073-2080.

12. Lehrke S, Mazhari R, Durand DJ, Zheng M, Bedja D, et al. (2006) Aging impairs the beneficial effect of granulocyte colony-stimulating factor and stem cell factor on post-myocardial infarction remodeling. Circ Res 99: 553-560.

13. Ayala-Lugo A, Tavares AM, Paz AH, Alegretti A, Miquelito L, et al. (2011) Age-dependent availability and functionality of bone marrow stem cells in an experimental model of acute and chronic myocardial infarction. Cell Transplant 20: 407-419.
14. Springer ML, Sievers RE, Viswanathan MN, Yee MS, Foster E, et al. (2005) Closed-chest cell injections into mouse myocardium guided by high-resolution echocardiography. Am J Physiol Heart Circ Physiol 289: H1307-1314.

15. Zhang Y, Sievers RE, Prasad M, Mirsky R, Shih H, et al. (2011) Timing of bone marrow cell therapy is more important than repeated injections after myocardial infarction. Cardiovasc Pathol 20: 204-212.

16. Takagawa J, Zhang Y, Wong ML, Sievers RE, Kapasi NK, et al. (2007) Myocardial infarct size measurement in the mouse chronic infarction model: comparison of area- and length-based approaches. J Appl Physiol 102: 2104 2111.

17. Luptak I, Yan J, Cui L, Jain M, Liao R, et al. (2007) Long-term effects of increased glucose entry on mouse hearts during normal aging and ischemic stress. Circulation 116: 901-909.

18. Kissel CK, Lehmann R, Assmus B, Aicher A, Honold J, et al. (2007) Selective functional exhaustion of hematopoietic progenitor cells in the bone marrow of patients with postinfarction heart failure. J Am Coll Cardiol 49: 2341-2349.

19. Sharpless NE, Depinho RA (2007) How stem cells age and why this makes us grow old. Nat Rev Mol Cell Bio 8: 703-713.

20. Edelberg JM, Tang L, Hattori K, Lyden D, Rafii S (2002) Young adult bone marrow-derived endothelial precursor cells restore aging-impaired cardiac angiogenic function. Circ Res 90: E89-93.

21. Pallante BA, Duignan I, Okin D, Chin A, Bressan MC, et al. (2007) Bone marrow Oct3/4+ cells differentiate into cardiac myocytes via age-dependent paracrine mechanisms. Circ Res 100: e1-11.

22. Rossi DJ, Bryder D, Seita J, Nussenzweig A, Hoeijmakers J, et al. (2007) Deficiencies in DNA damage repair limit the function of haematopoietic stem cells with age. Nature 447: 725-729.

23. Collado M, Blasco MA, Serrano M (2007) Cellular senescence in cancer and aging. Cell 130: 223-233.

24. Heeschen C, Lehmann R, Honold J, Assmus B, Aicher A, et al. (2004) Profoundly reduced neovascularization capacity of bone marrow mononuclear cells derived from patients with chronic ischemic heart disease. Circulation 109 1615-1622. 